\title{
Control Strategy for a Modified Cascade Multilevel Inverter with Dual DC Source for Enhanced Drivetrain Operation
}

\author{
Maciej Bendyk, Patrick Chi-Kwong Luk, Mohammed Alkhafaji \\ Electric Power and Drives Group, Power Engineering Centre, Cranfield University, Cranfield, MK43 0AL, U.K. \\ E-mail: m.s.bendyk@gmail.com,p.c.k.luk@cranfield.ac.uk, m.h.alkhafaji@cranfield.ac.uk,
}

\begin{abstract}
This paper presents a new control strategy for a modified cascade multilevel inverter used in drivetrain operations. The proposed inverter is a three-phase bridge with its dc link fed by a dc source (battery), and each phase seriesconnected respectively to an H-bridge fed with a floating dc source (ultracapacitor). To exploit the potentials of the inverter for enhanced drivetrain performance, a sophisticated yet efficient modulation method is proposed to optimise energy transfer between the dc sources and with the load (induction motor) during typical operations, and to minimise switching losses and harmonics distortion. Detailed analysis of the proposed control method is presented, which is supported by experimental verifications.
\end{abstract}

Index Terms-Multilevel inverter, dual energy source, switching strategy, drivetrain.

\section{INTRODUCTION}

The performance of conventional drivetrains is usually limited by the capability of the energy sources such as batteries when the electric motor can easily be overloaded for short durations. In addition, high dc voltage is required to overcome the back electromotive force (EMF) generated by the motor during high speed. To achieve high power with reasonable efficiency it is required to use high voltage, which is difficult to attain with low voltage batteries or fuel cells [1-2]. A common approach is to incorporate high power density sources such as ultracapacitors (UC). The most established solution that allows power flow between batteries and UC is realized by parallel connection of bidirectional DC/DC converters [3-5]. The hybridization of battery together with UC was found as effective way to reduce peak battery current and increasing its life [6]. This type of interface between UC and battery requires complex control to stabilize dc bus voltage during transients and to use of bulky inductors [7-9]. More recently, hybrid configurations with multi-level inverters are proposed to provide better utilization of battery and UC as well to increased available voltage output.

Incorporation of multilevel inverters has shown the potential benefits of reducing torque ripple, harmonic distortion and switching losses [10-12]. One of proposed concept is to implement three phase boost inverter based on multilevel inverter architecture that do not require bulky inductors [13]. This structure prove is capable to increase inverter output voltage but presented system use only low frequency switching at fundamental frequency and energy transfer between sources is omitted The application with power flow control for multilevel inverter with multiple sources has been also introduced [14]. The strategy is based on instantaneous reactive power theory where bulk section of inverter is switched at fundamental frequency and conditioning inverter controls real and reactive power flow. The control strategy is limited to system supplied by two Neutral Point Clamped (NPC) inverters and do not emphasise modulation method for full amplitude variation of UC. The direct UC integration was also implemented for wind power systems to mitigate power fluctuations [15]. The proposed solution incorporate UC into 3-level flying capacitor multilevel inverter and focus on modulation method for UC variable voltage. The power flow for this implementation is not derived and full potential of voltage sources is not utilized.

In this paper authors present a detailed analysis on a modified cascade multilevel inverter supplied by a dual-dc source against realistic constraints. Based on the voltage vector and active power analysis, a new control strategy that optimizes the inverter performance in the whole operating range with power flow control between sources is proposed and implemented. Presented in this paper modulation strategy intent to maximize available amplitude of output voltage and its quality, and at the same allows access to total energy stored in UC. This paper aims to find solution that will provide efficient and robust system that can be adapted to existing hardware.

\section{TOPOlOGy OF INVERTER MOtor Drive}

The multilevel inverter under study is shown in Fig.1. It consists a three-phase bridge with the main dc link fed by a single dc source (battery), and each phase series-connected respectively to an H-bridge fed with a floating dc source (UC) where the voltage is allowed to vary depending on energy stored. This type of modified cascade multilevel inverter is selected since the structure is known to deliver a high number of output voltage levels for relatively low number of switches, and that the dc sources are isolated [16-17]. The output phase voltage $\left(V_{a n}, V_{b n}, V_{c n}\right)$ of the inverter in reference to the centre point " $n$ " of the main voltage source can be described as a function of battery voltage $\left(V_{b a t}\right)$, UC voltages $\left(V_{u c_{A}}, V_{u c_{B}}, V_{u c_{C}}\right)$ and switch combinations ( $S 1, S 2, S 3, A 1, A 2, B 1, B 2, C 1, C 2)$ as summarised by the following equations:

$V_{a n}=\frac{1}{2} V_{b a t}(2 \times S 1-1)+V_{u c_{A}}(A 2-A 1)$ 


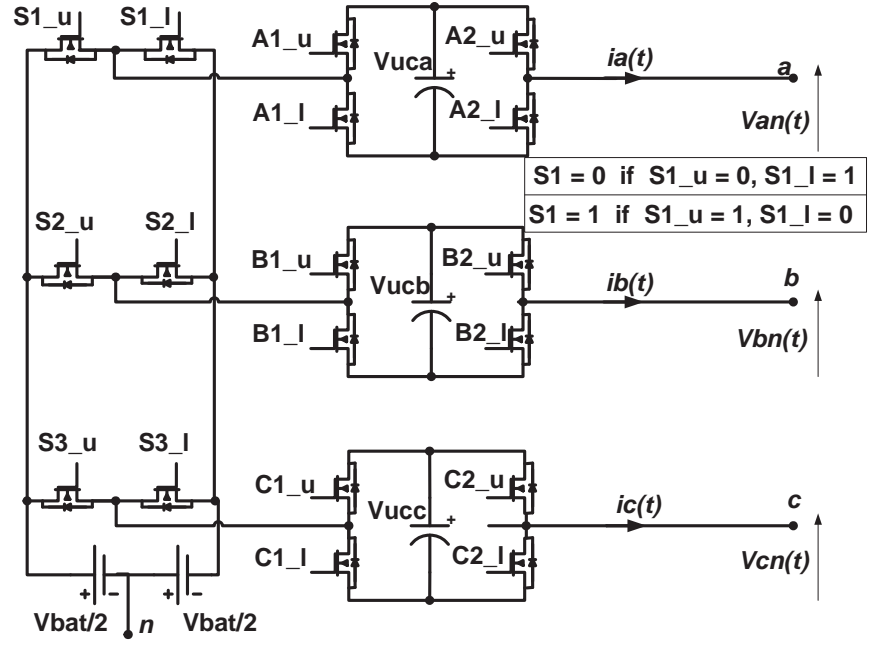

Fig. 1: Modified cascade inverter consisting 3-phase inverter and three H-bridges.

$$
\begin{aligned}
V_{b n} & =\frac{1}{2} V_{b a t}(2 \times S 2-1)+V_{u c_{B}}(B 2-B 1) \\
V_{c n} & =\frac{1}{2} V_{b a t}(2 \times S 3-1)+V_{u c_{C}}(C 2-C 1)
\end{aligned}
$$

Converting those three-phase voltages in time domain by Clark alpha-beta transformation into stationary space vectors two phase plane $\left(V_{\text {alpha }}, V_{\text {beta }}\right)$, it becomes possible to generate 512 voltage vectors. It is because for nine top and bottom switches there are $2^{9}$ combinations.

$$
\begin{aligned}
V_{\text {alpha }} & =\frac{2}{3}\left(V_{a n}-\frac{1}{2} V_{b n}-\frac{1}{2} V_{c n}\right) \\
V_{\text {beta }} & =\frac{\sqrt{3}}{3}\left(V_{b n}-V_{c n}\right)
\end{aligned}
$$

Since the aim of UC is to provide additional power during acceleration or to recuperate energy from braking, their voltage will vary depending on state of charge. This results in available voltage vectors coordinates being not constant and the traditional Space Vector Modulation (SVM) for multilevel inverters cannot be implemented [18-20]. In Fig.2 examples of vectors coordinates for three different voltage ratios between inverter sources. To simplify analysis it is assumed that the voltages on all three sources that supply the H-bridges are equal since the regulator controls them to the same capacitor reference voltage.

Simultaneously switching different combinations of the three-phase inverter and the $\mathrm{H}$-bridges provides the enhanced capability to control power flow between batteries, UC and the motor and at the same time to generate precise voltage vectors with reference amplitude.

\section{Switching Strategies}

For voltage ratios between the main voltage source and $\mathrm{UC}\left(V_{b a t} / V_{u c}\right)$ that are integer and if that ratio is lower or equal to four it is possible to achieve redundant vectors. For non-integer supply voltage ratios each vector is unique since it can be generated only by one switching combination (without considering individual redundant switching states for H-bridges and three-phase bridge). It can be observed

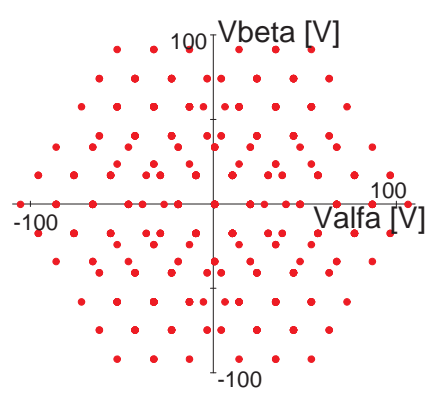

(a) Volatge ratio $V_{b a t}=3.4 V_{u c}$

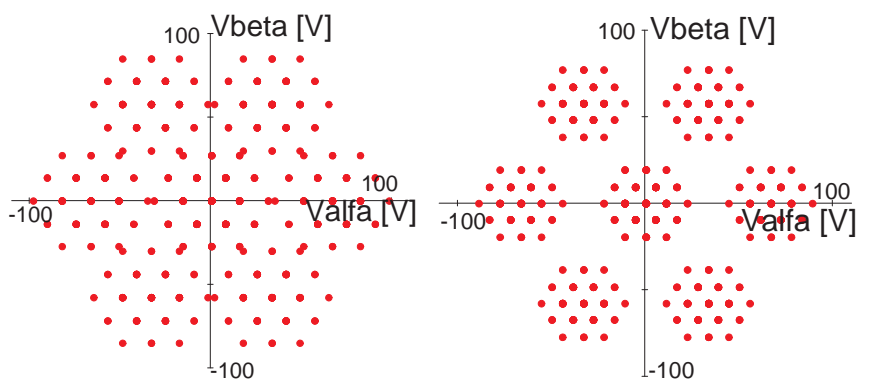

(b) Voltage ratio $V_{b a t}=4.2 V_{u c}$

(c) Voltage ratio $V_{b a t}=6 V_{u c}$

Fig. 2: Set of available voltage vectors coordinates (red dots) calculated for different dc voltage ratios on stationary alpha beta plane base on equations (1-5) .

in Fig.2 that with the increase of the voltage ratio between inverter sources the gaps between vectors coordinates start to appear. This means that modulated vectors with circular trajectory that have transitions through those areas, the closest vectors will require change in high number of switching states both in three-phase bridge and H-bridges. This might cause high switching losses and large ripples in the output voltage since transition through the undesirable vectors is needed. Additionally modulation solution between the closest vector could have different power share between sources from the required. To overcome this problem the strategy where inverter sections are separated so either H-bridges or three-phase bridge are switched at fundamental frequency and remaining part is responsible for SVM has been implemented. As shown in Fig.3 (a) for higher voltage ratio between sources the H-bridges vector envelopes in combinations with vectors from 3-phase bridge are limited to hashed area. In opposite situation when the ratio between the sources gets smaller the H-bridges hexagon envelope for the closest vectors in three-phase bridge starts to overlap as shown in Fig.3 (b). In this case depending when vector transition in three-phase bridge occurs the proportion of power delivered between sources might be adjusted. To create switching strategy for the hybrid cascade multilevel inverter where amplitude of auxiliary voltage source is at last $50 \%$ lower than the main source voltage and can go down to less than 5\%, six main operating modes are identified. By finding the output voltage limitation for each mode and expected output power, optimum configuration can be selected during the whole operating range for various UC voltage. Calculation for the power distribution is simplified by the assumption that the motor current vector $(I)$ seen by inverter is ideally sinusoidal. 


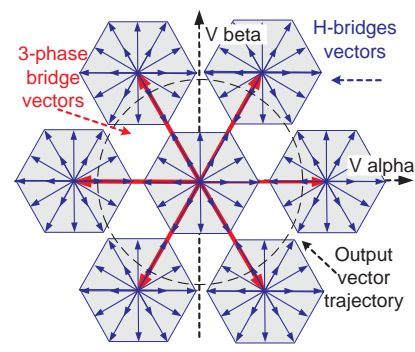

(a) Voltage ratio $V_{b a t}=6 V_{u c}$ (b) Voltage ratio $V_{b a t}=2.1 V_{u c}$

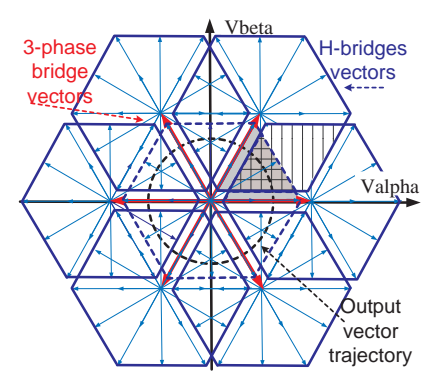

Fig. 3: Overlapping of voltage vectors from $\mathrm{H}$-bridges for different vectors from 3-phase bridge when the voltage ratio between the sources vary.

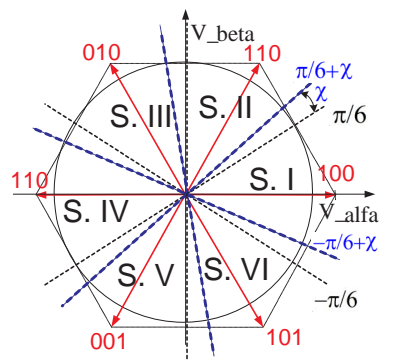

(a) Phase shift in alpha beta plane

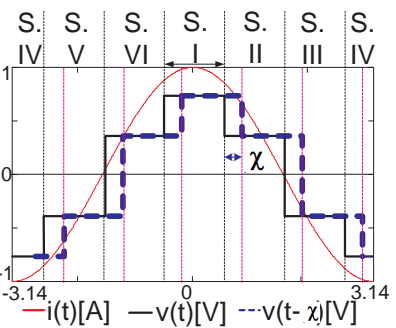

(b) Phase shift in time domain
Fig. 4: Voltage vectors and output waveforms for 3-phase bridge with sector phase shift (S. - Sector).

MODE I: Only three-phase bridge operates in SVM similar to standard three-phase voltage source inverter. All H-bridges will stay in zero vector position ( $A 1, A 2, B 1, B 2, C 1, C 2$ are 0 - "000000"), meaning that only lower switches are on. For this switching strategy inverter has only six active and two zero voltage vectors. The amplitude of the active vectors is $2 / 3$ of supply voltage. For standard SVM in this mode without over modulation the maximum amplitude of rotary voltage vector equals radius of the circle that can be inscribed inside hexagon $\left(V_{M I \max }=V_{\text {bat }} / \sqrt{3}\right)$.

For inverter operations when only three-phase bridge is active, the power delivered from dc source $\left(P_{b a t}\right)$ has to be equal to power dissipated at load $\left(P_{\text {out }}\right)$ if inverter losses are omitted. This can be presented as a simple product of battery current $\left(I_{b a t}\right)$ and its voltage $\left(V_{b a t}\right)$ or product of reference voltage $\left(V_{r e f}\right)$ vector, motor current in stationary alpha-beta plane $(I)$ and power factor $(\cos (\phi))$.

$P_{\text {out }}=P_{b a t}=V_{\text {bat }} I_{b a t}=\frac{3}{2} V_{\text {ref }} I \cos (\phi), \quad P_{u c}=0$

MODE II: In this mode three-phase bridge is switched at fundamental frequency and remaining $\mathrm{H}$-bridges operate in SVM mode. Each active vector of three-phase bridge is switched on for one sixths of fundamental frequency forming six step waveform. The H-bridges are mainly used to minimise voltage error and harmonic, and depends on amplitude of reference voltage to sink or source energy. In Fig.4 six sectors and corresponding voltage vectors for three-phase bridge are illustrated. Additionally the phase shift angle $(\chi)$ has been

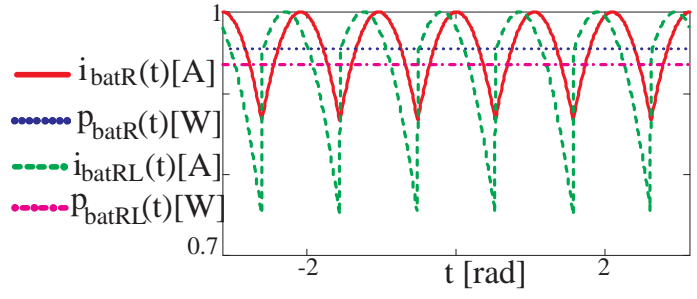

Fig. 5: Current seen by main source (battery) for resistive load $i_{\text {bat }} R(t)$ and for inductive load $i_{b a t} L R(t)$ and corresponding output power.

marked to present how the sectors in which voltage vectors are activated can be adjusted according to the output power requirement. The power delivered by the main source can be calculated as integral of current seen by the source and product of its voltage as presented in equation (7).

$P_{b a t}=\frac{3}{\pi} \int_{-\frac{\pi}{6}}^{\frac{\pi}{6}} V_{b a t} I \cos (\omega t+\phi+\chi) d t=\frac{3}{\pi} V_{b a t} I \cos (\phi+\chi)$

In Fig. 5 the current that is sourced by battery has been presented to illustrate the influence of power factor on output power. Introduced phase shift $(\chi)$ angle has similar effect on main source power.

In Fig.6 the graph with possible switching combinations for active $100(S=1, S 2=0, S 3=0)$ voltage vector in threephase bridge and its limiting hexagon is presented. It is noted that for this mode the key to operate inverter is to find limiting boundary. The maximum amplitude of output voltage vector is $2\left(V_{b a t}+2 V_{u c}\right) / 3$ so the maximum output voltage has to be smaller than $V_{M I I m a x}=\left(V_{b a t}+2 V_{u c}\right) / \sqrt{3}$. Additionally the smallest voltage vector in this configuration has to be higher than $V_{\text {MIImin }}=2\left(V_{b a t}-2 V_{u c}\right) / 3$. In Fig.6 the grey ring marks the amplitude of voltage vector that can be generated through whole sector $(-\pi / 6,+\pi / 6)$ for vector '100'. For a set reference within the grey area it is possible to add or subtract phase shift angle " $\chi$ " to either increase (only if $\cos (\phi)<1$ ) or to reduce power delivered by the main source. The maximum phase shift angle can be calculated from following equations where the smallest value should be used.

$\chi_{1}=\arcsin \left(\frac{2 V_{u c}}{\sqrt{3} V_{\text {ref }}}\right)-\frac{\pi}{6}, \chi_{2}=\frac{\pi}{6}-\arcsin \left(\frac{V_{b a t}-2 V_{u c}}{\sqrt{3} V_{\text {ref }}}\right)$

MODE III: Modulation strategy where H-bridges are only active in SVM and three-phase bridge is in '000' zero vector state (or ' 111 '). The amplitude of the rotary output voltage vector is limited to $V_{\text {MIIImax }}=2 V_{u c} / \sqrt{3}$ and the whole power required by output is delivered by UC $\left(P_{u c}\right)$.

$$
P_{u c}=\frac{3}{2} V_{\text {ref }} I \cos (\phi)=P_{\text {out }}, P_{\text {bat }}=0
$$

The SVM for H-bridges needs additional control to keep all three UC voltage at same level. For normal operations the symmetrical switching of voltage vectors provides good results but drift might appear for variable load. In Fig.7 two switching combinations (' $a$ ' and ${ }^{6} b$ ) that can be used to generate reference voltage vector for 2-level and 3-level operations are presented. In case capacitor exceeds set reference threshold then in adequate sector the switching configuration is changed 


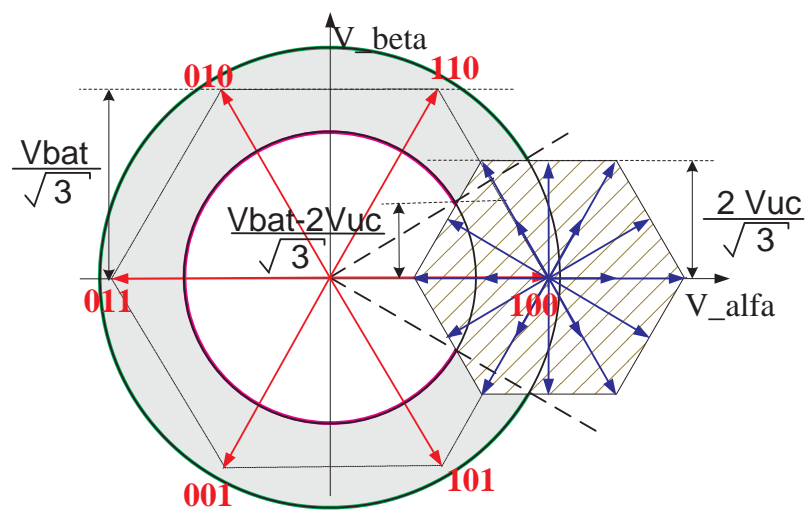

Fig. 6: Modulations limits for strategy with three phase bridge in six step mode and H-bridges in SVM (grey ring), red vectors represents switching states for three phase bridge, blue vectors are switching states of three H-bridges.

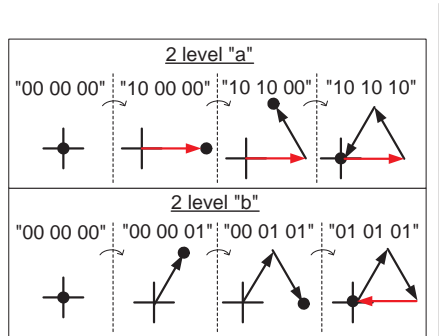

(a) 2-level SVM for $V_{\text {ref }}<V_{u}$

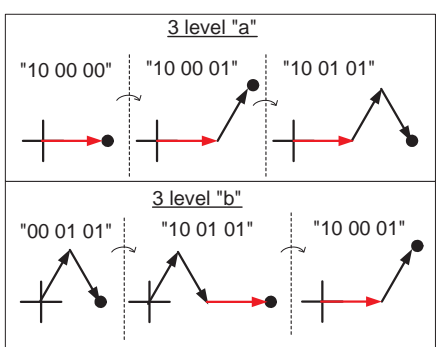

(b) 3-Level SVM for $V_{\text {ref }}>$
Fig. 7: Possible alternative voltage vectors sequence for 3phase H-bridge section to vary power delivered by individual H-bridge UC for 2-level and 3-level operations.

so the current seen by capacitor either change direction or is switched for less time (' $b$ combination).

MODE IV: The Hbridges operates in six-step mode at fundamental frequency where only one $\mathrm{H}$-bridge is active at the same time (each H-bridge active through $1 / 3$ of period) and a three-phase bridge is compensating harmonics by SVM. Similarly to MODE II the active power delivered by UC can be calculated as an integral of active power seen by three $\mathrm{H}$ bridges what is simplified to equation (10).

$P_{u c}=\frac{1}{\pi}\left(V_{u c_{A}}+V_{u c_{B}}+V_{u c_{C}}\right) I \cos (\phi+\chi)$

The profile of instantaneous power seen by each source and its average value is presented in Fig.8. The maximum output voltage in this configuration equals to $V_{M I V \max }=$ $\left(V_{b a t}+V_{u c}\right) / \sqrt{3}$. Additionally it is possible to change sign of active power flowing from UC by setting phase shift angle $\chi$ opposite to motor current vector $(\chi=\phi \pm \pi)$ that allows to generate the maximum output voltage limited to $V_{N M I V \max }=V_{b a t}-V_{u c} / \sqrt{3}$ as shown in Fig. 9. For the ratio between main source and UC higher than two, the modulation can be performed through the whole sector. Power sharing control by phase shifting " $\chi$ " for amplitude of reference voltage $V_{\text {ref }}<V_{N M I V \max }$ can be performed for any angle. If the reference voltage is higher than $V_{N M I V \max }$ the maximum phase shift is limited by ratio between amplitude

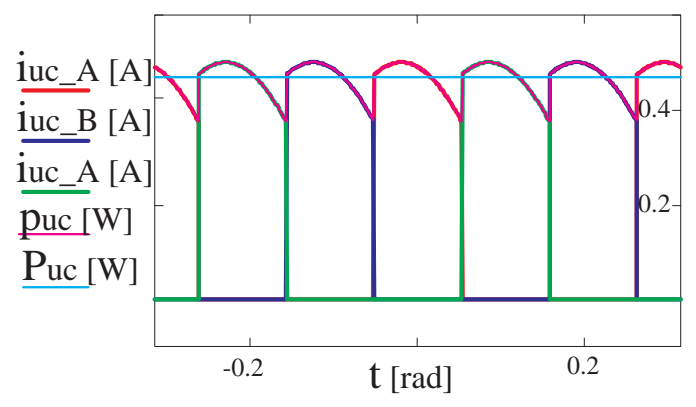

Fig. 8: Currents sourced by UC $\left(i_{u c_{A}}, i_{u c_{B}}, i_{u c_{C}}\right)$ in mode IV and their total instantaneous $\left(p_{u c}\right)$ and average power $\left(P_{u c}\right)$ from H-bridges.

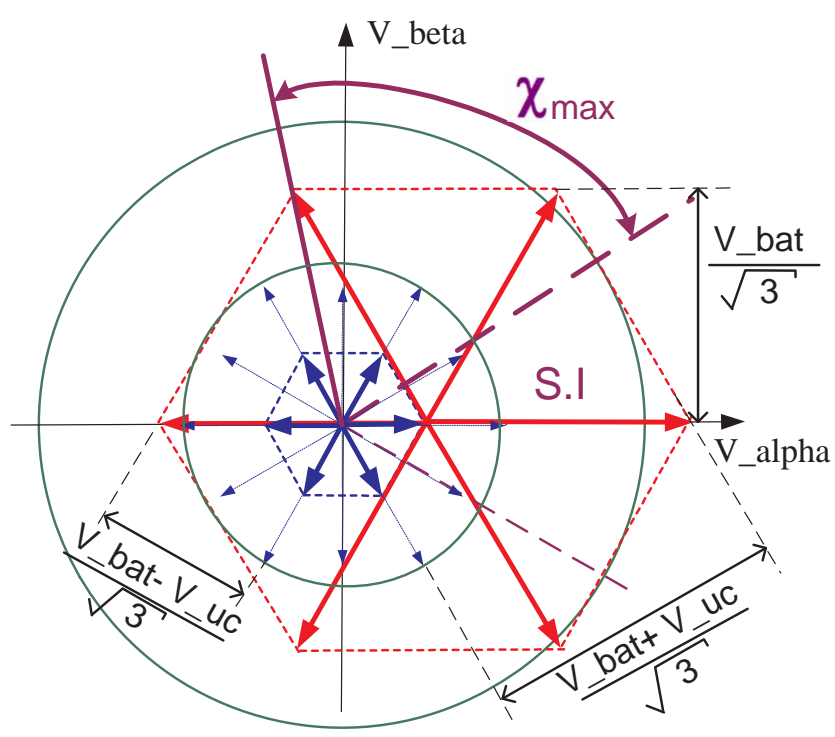

Fig. 9: Limitation of modulation scheme with H-bridges switched at fundamental frequency (mode IV). Blue vectors are switching combinations of three $\mathrm{H}$-bridges, red vectors are switching combinations of three phase bridge.

of main dc source and reference vector according to equation (11). Additionally for $V_{r e f}>V_{N M I V \max }$ maximum phase shift angle has been defined as $\chi_{\max }$ to simplify control.

$$
\begin{array}{r}
\chi=\arcsin \left(\frac{V_{b a t}}{\sqrt{3} V_{\text {ref }}}\right)-\frac{\pi}{6} \\
\chi_{\text {max }}=\operatorname{arctg}\left(\frac{\sqrt{3} V_{b a t}}{2 V_{u c}-V_{b a t}}\right)-\frac{\pi}{6}
\end{array}
$$

MODE V: To increase power flow from H-bridges, it is possible to extend mode IV by modifying six step switching sequence with two H-bridges active at the same time. Since two adjacent vectors are switched on together, the operating sector shifts by $\pi / 6$. Solving integral of the instantaneous power seen by all three H-bridges gives equation (12) that calculates power sourced by UC. The profile of instantaneous power, its sum and average value is shown in Fig.10.

$P_{u c}=\frac{\sqrt{3}}{\pi}\left(V_{u c_{A}}+V_{u c_{B}}+V_{u c_{C}}\right) I \cos (\phi+\chi)$

In Fig. 11 we can find that the maximum modulated voltage is $V_{M V \max }=2\left(V_{b a t}+V_{u c}\right) / 3$ and for six-step waveform phase 


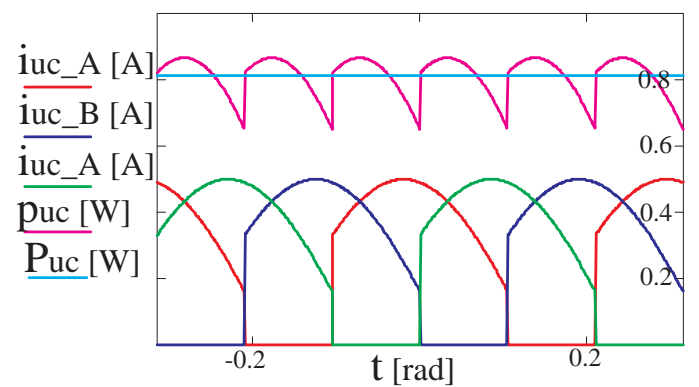

Fig. 10: Current sourced by UC $\left(i_{u c_{A}}, i_{u c_{B}}, i_{u c_{C}}\right)$ in mode V and corresponding instantaneous power from three UC $\left(p_{u c}\right)$, and average power from H-bridges $\left(P_{u c}\right)$

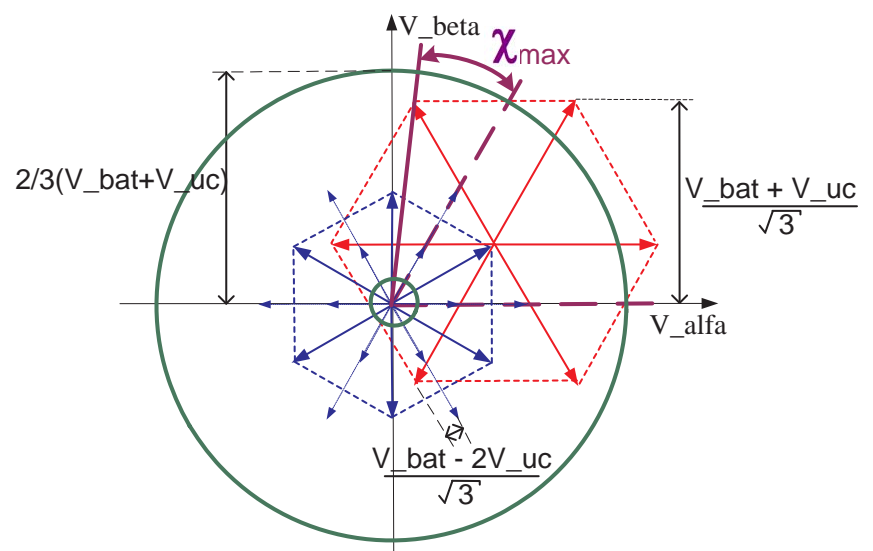

Fig. 11: Limitation of modulation scheme with H-bridges switched at fundamental frequency (mode V). Blue vectors are switching combinations of three H-bridges, red vectors are switching combinations of three phase bridge.

shifted by $\pm \pi$ the output has to be smaller than $V_{N M V \max }=$ $\left(V_{b a t}-2 V_{u c}\right) / \sqrt{3}$. The phase shift power control is limited by equation (13) where maximum angle to simplify control is limited to $\chi_{\max }$.

$$
\begin{array}{r}
\chi=\arcsin \left(\frac{V_{b a t}+V_{u c}}{\sqrt{3} V_{r e f}}\right)-\frac{\pi}{3} \\
\chi_{\max }=\operatorname{arctg}\left(\frac{V_{b a t}+V_{u c}}{\sqrt{3}\left(V_{u c}-V_{b a t}\right)}\right)-\frac{\pi}{3}
\end{array}
$$

MODE VI: To achieve maximum output power from $\mathrm{H}$ bridges it is proposed to keep all three UC active in six step mode at fundamental frequency. The power by H-bridges doubles in comparison with mode IV as predicted by equation (14), and is shown in Fig 12.

$P_{u c}=\frac{2}{\pi}\left(V_{u c_{A}}+V_{u c_{B}}+V_{u c_{C}}\right) I \cos (\phi+\chi)$

Fig.13 shows that the maximum modulated voltage $V_{M V I m a x}=\left(V_{b a t}+2 V_{u c}\right) / \sqrt{3}$ and for six-step waveform phase shifted by $+\pi$ or $-\pi$ the output has to be smaller than $V_{N V I m a x}=\left(V_{b a t}-2 V_{u c}\right) / \sqrt{3}$. The available phase shift power control for given reference vector becomes limited by equation (15):

$$
\chi=\arcsin \left(\frac{V_{\text {bat }}}{\sqrt{3} V_{\text {ref }}}\right)-\frac{\pi}{6}
$$

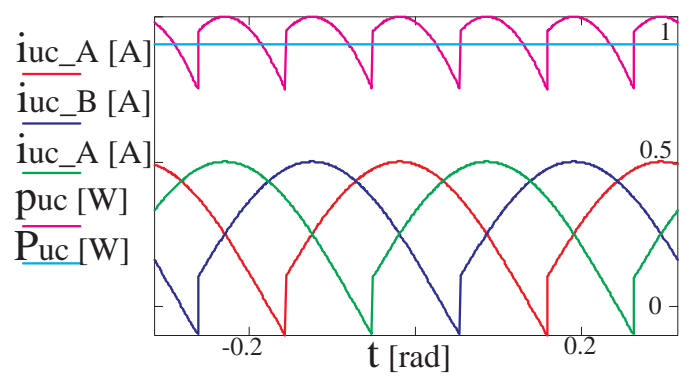

Fig. 12: Current sourced by UC $\left(i_{u c_{A}}, i_{u c_{B}}, i_{u c_{C}}\right)$ in mode VI and corresponding instantaneous power $\left(p_{u c}\right)$ from three UC, and average power $\left(P_{u c}\right)$ from H-bridges.

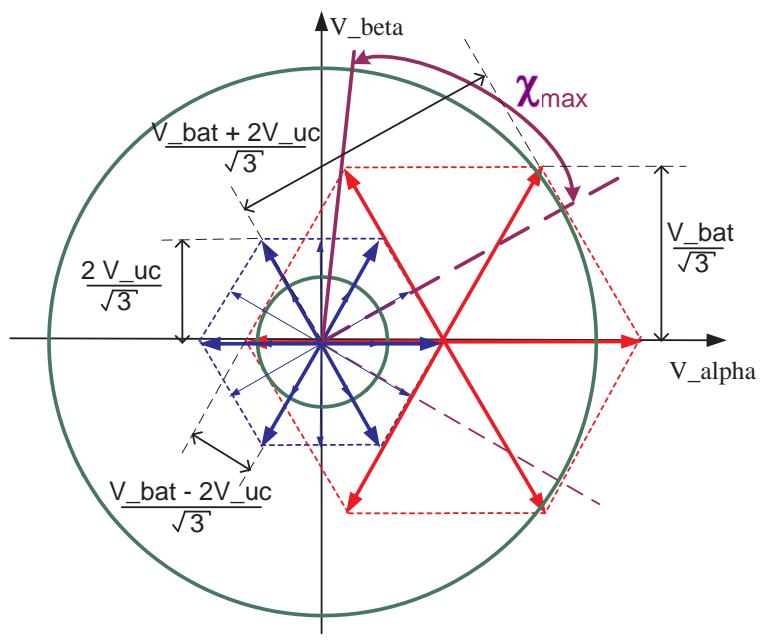

Fig. 13: Limitation of modulation scheme with H-bridges switched at fundamental frequency (mode VI). Blue vectors are switching combinations of three $\mathrm{H}$-bridges, red vectors are switching combinations of three phase bridge.

$$
\chi_{\max }=\operatorname{arctg}\left(\frac{\sqrt{3} V_{b a t}}{4 V_{u c}-V_{b a t}}\right)-\frac{\pi}{6}
$$

The above analysis provides the voltage limits, which depend on UC state of charge, for all switching strategies as shown in Fig.14. By selecting suitable strategy it is possible to modulate voltage vector from $0 \mathrm{~V}$ up to $\left(V_{b a t}+2 V_{u c}\right) / \sqrt{3}$. The negative voltage symbolizes modulation with 180deg phase shift $(\chi= \pm \pi)$. To understand different power sharing for above switching modes, example calculations of power delivered by sources for variable phase shift angle between $(\chi<-\pi / 6,+\pi / 6)$ and with power factor $\cos (\phi)=0.966$ are shown in Fig.15 $\left(V_{b a t}=100 \mathrm{~V}, V_{u c}=50 \mathrm{~V}\right)$. As presented it is not always possible with phase shift control to produce required power from sources.

For optimum inverter performance it is desire to use modulation with smallest voltage vectors (H-bridges) to perform SVM and 3 phase bridge switched with six step (mode II). The phase shift power control with " $\chi$ " angle is limited by hexagon boundaries of voltage vectors specific to each mode as presented in Fig.6,9,11 and 13 (most significantly in mode II). Also for a high voltage ratio between two sources it might become impossible to modulate circular reference voltage vector with every modulation scheme. Since inverter 


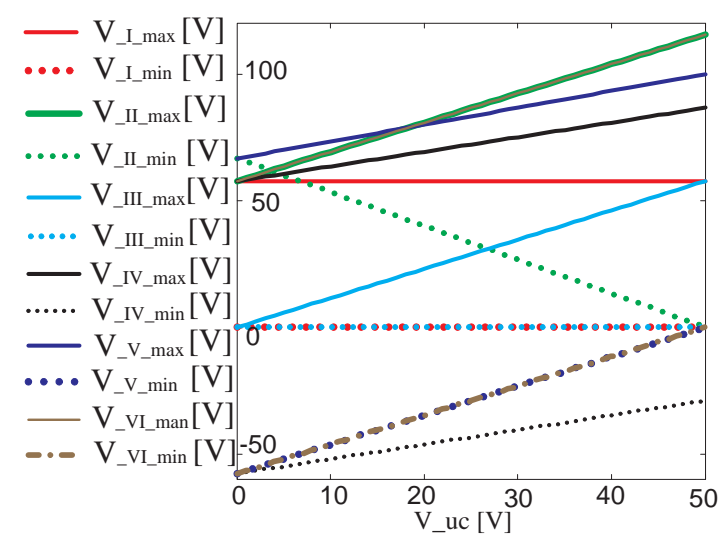

Fig. 14: Voltage limits for identified switching configuration in relation to auxiliary source voltage Vuc, solid line maximum voltage, dotted line minimum voltage.

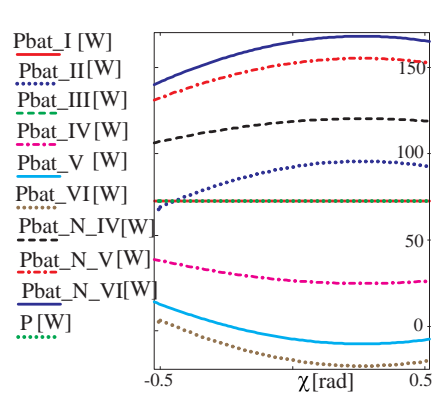

(a) Power delivered by battery

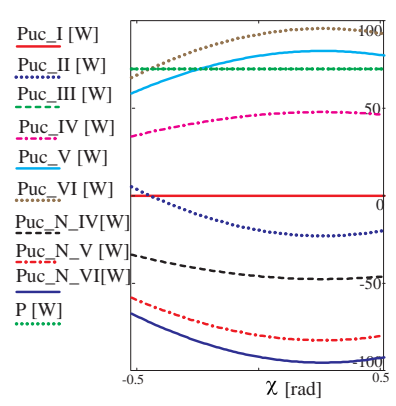

(b) Power delivered by UC
Fig. 15: Power sharing regulation by phase shift angle " $\chi$ " for identified switching modes (power factor $\cos (\phi)=0.966$ )

has six symmetrical sectors it is proposed to alternate between two switching modes twice per every one sixth of the period from limited modulation mode to the one that can deliver required voltage vector. To control power the switch angle $\alpha$ has been defined that can be set from 0 up to $\pi / 6$ as shown in Fig.16. In this modulation scheme output voltage is limited by the amplitude of the smallest maximum output voltage from two selected switching strategies. By solving integrals of instantaneous power for two combined modulation strategies alternating at defined angle $(\alpha)$ the following example power control equations are formulated: Mode I and III:

$P_{b a t}=\frac{6}{\pi} P_{o u t} \times \alpha, \quad P_{u c}=\left(1-\frac{6}{\pi} \times \alpha\right) P_{\text {out }}$
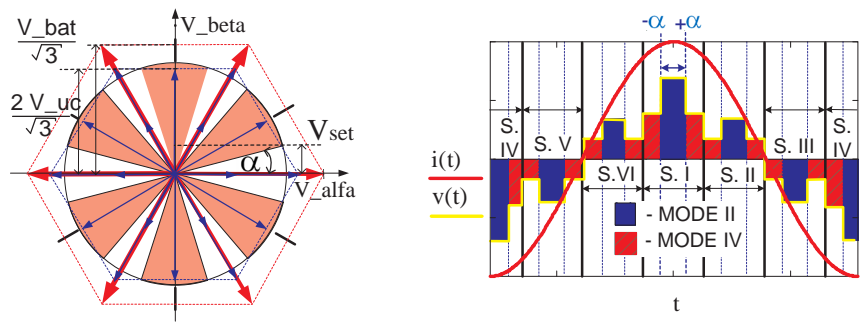

(a) Presented in alpha beta coordi-(b) Motor current and mixed six step voltnates age for alpha axis in time domain

Fig. 16: Strategy to switch between to modulation modes.

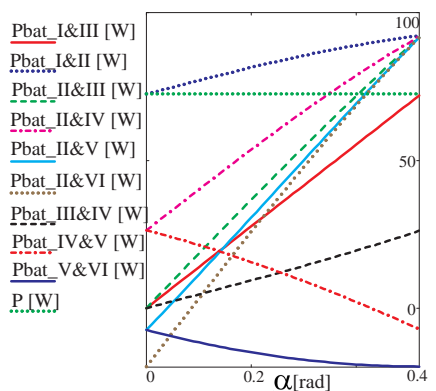

(a) Power delivered by battery

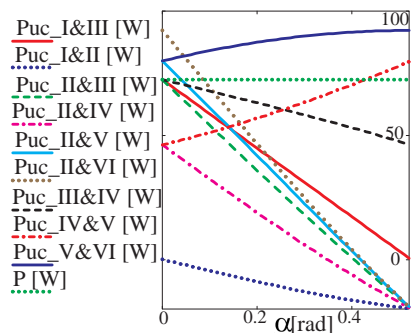

(b) Power delivered by UC
Fig. 17: Power sharing regulation in mixed mode switching for various switching combinations (power factor $\cos (\phi)=0.966$ ).

Mode I and II:

$P_{b a t}=\frac{3}{\pi} V_{b a t} I \cos (\phi+\chi) 2 \sin (\alpha)+\frac{3}{2} V_{\text {ref }} I \cos (\phi)\left(1-\frac{6}{\pi} \alpha\right)$

Mode II and III:

$P_{b a t}=\frac{3}{\pi} V_{b a t} I \cos (\phi+\chi) 2 \sin (\alpha)$

Mode II and IV:

$$
\begin{gathered}
P_{b a t}=\frac{3}{\pi} V_{b a t} I \cos (\phi+\chi) 2 \sin (\alpha)+P_{\text {out }} \\
-\frac{1}{\pi}\left(V_{u c_{A}}+V_{u c_{B}}+V_{u c_{C}}\right) I \cos (\phi+\chi)(1-2 \sin (\alpha))
\end{gathered}
$$

Mode V and VI:

$$
\begin{aligned}
& \quad P_{u c}=\frac{1}{\pi}\left(V_{u c_{A}}+V_{u c_{B}}+V_{u c_{C}}\right) I \cos (\phi+\chi)(\sin (\alpha) \\
& +\sqrt{3} \cos (\alpha))
\end{aligned}
$$

An example of possible power values for various switching combinations with parameters $\chi=0, \cos (\phi)=0.966, V_{b a t}=$ $100 \mathrm{~V}, V_{u c}=50 \mathrm{~V}$ is presented in Fig. 17, it is possible to notice that the strategy allows complete power sharing in whole range of available power.

\section{IMPLEMENTATION OF MODULATION STRATEGY}

To meet above requirements the control system for hybrid cascade inverter with multiple sources has been designed as shown in figure 18. Presented system consists of three main functional blocks with hierarchical structure [21]: Power management with torque and flux regulation; a modulation strategy control; SVM with power share control; Direct Torque Control (DTC) with torque and flux estimator. Based on presented analysis the control switching algorithm has been developed. In Fig.19, the block diagram of the proposed voltage vector modulator is presented with following blocks:

1. Cartesian to polar transformation to calculate angular position of reference vector in stationary reference plane $(\alpha, \beta)$. 2. Comparator module generating switch signal to change modulation mode when voltage vector is crossing set $\alpha$ angle. 3. Lookup table with six step switch combination and six modulation strategies (from MODE I to MODE VI). The function includes voltage vector angle comparator to find switch combination adequate to sector. The voltage angle signal includes added phase shift " $\chi$ ".

4. Estimator of six step voltage in alpha beta plane base on 


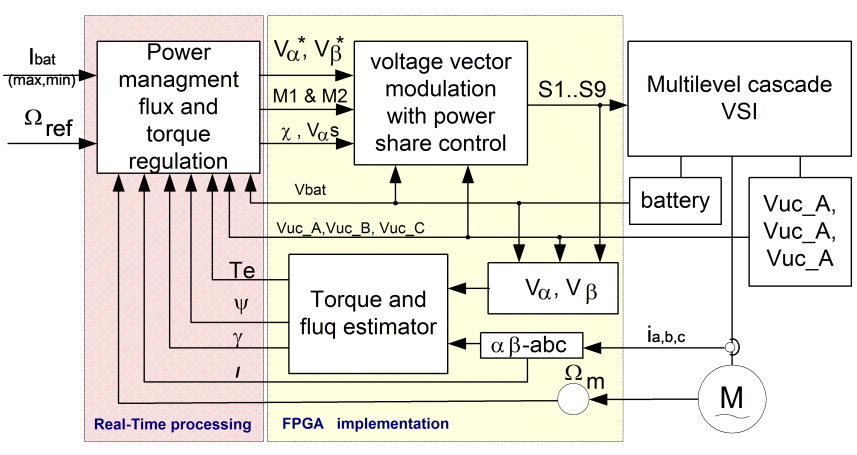

Fig. 18: Block diagram of cascade multilevel inverter motor drive with power flow management.

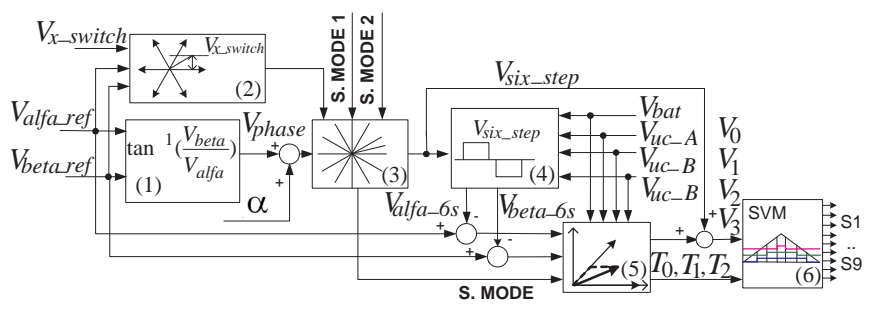

(a) Modulator block diagram

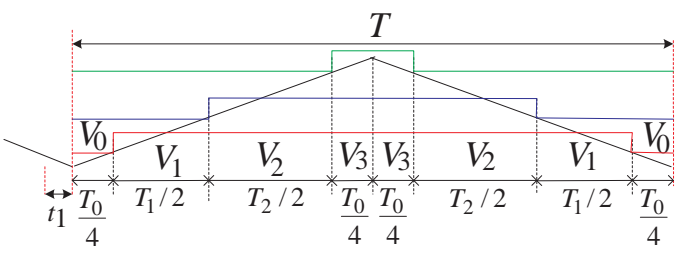

(b) SVM timing signals

Fig. 19: Block diagram of modulation strategy for cascade multilevel inverter with variable sources voltage and power flow control.

equations (1-5) and switch combination from block 3 .

5. SVM block to modulate remaining voltage error. The block include lookup table to find adequate voltage vectors and perform dwell times calculations for SVM.

6. Three phase SVM with symmetrical placement of zero vector and 10 bit counter to generate switching pulses for corresponding vectors and dwell times [22].

The whole algorithm is synchronized with counter (block 6) and takes one count before counter overflow $(t 1)$ to calculate new switching pattern. The period $\mathrm{T}$ was set to $1024 \mathrm{us}$ with 1us resolution ( $t 1$ ) (Digital output card limitation). The above modulator has been incorporated into motor drive system with DTC and Power Management supervisory algorithm as shown in Fig.18. The Power Management is implemented in realtime system synchronized with SVM counter and base on selected operating modes. The power sharing control algorithm operates in three main steps: 1 . The output reference vector is compared with maximum voltage that can be generated by each modulation scheme. Switching modes that are not able to provide sufficient output voltage become inhibited for further calculations. 2. The limiting phase shift angles for remaining modulation schemes are calculated, and the limits for phase shift control of power share are found. 3. Based on reference

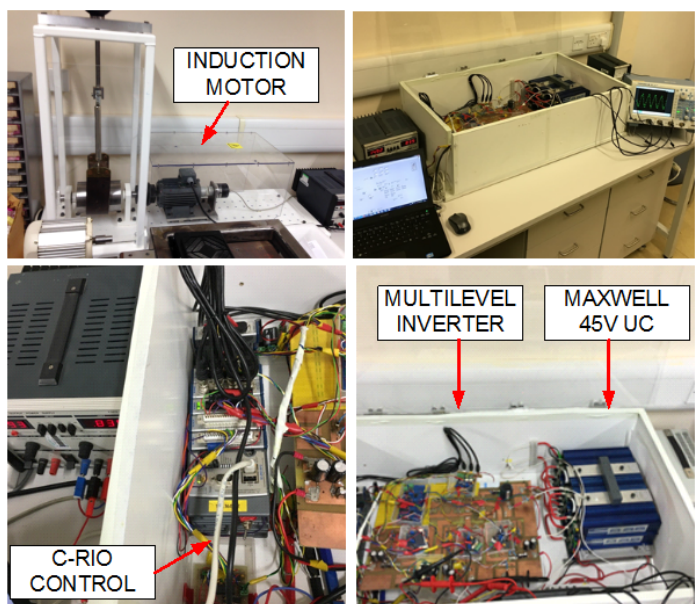

Fig. 20: Hardware picture of the setup.

torque, motor speed, dc sources voltage and motor current, the reference power for main and auxiliary inverter is calculated. For each mode the expected power share by each source is estimated in order to find the operating mode that can provide the requested power distribution between sources. The output from Power management module to the vector modulator includes voltage reference in alpha beta plane $\left(V_{\text {alfaref }}, V_{\text {betaref }}\right)$, two selected switching modes (S. MODE1 and S. MODE2), phase shift angle $(\chi)$ and angle $(\alpha)$ where modulation mode is changed from MODE1 to MODE2. Since it is desirable to use small vectors to minimise switching losses and distortions in output voltage, the modulation that use H-bridges in SVM is always prioritized (mode II and/or mode III).

\section{EXPERIMENTAL VALIDATION}

A prototype of the system is built for experimental validation. Fig. 20 shows the setup which includes: three-phase induction motor (delta configuration 230V, 370W, 2840rpm); modified cascade multilevel inverter; dc source $(60 \mathrm{~V} / 120 \mathrm{~V})$; three sets of 45V UC (Maxwell 19F UC) or $2 \mathrm{mF}$ electrolytic capacitors; voltage and current sensing circuit; National Instruments (NI) Real Time platform NI CRIO-9012 including Field-Programmable Gate Array (FPGA) (Virtex- 5 LX30) with 19200 LookUp Tables (LUTs) operating at $40 \mathrm{MHz}$.

The operation where three-phase bridge is switched at fundamental frequency is to be used during most of the inverter operations. Fig.21 presents the typical waveforms captured in mode II for two different phase shifts $(\chi)$. For the first maximum phase shift the current seen by the main source is minimized, while in second case the phase shift is optimized for battery maximum current (six step switching synchronized with phase of motor current). The change in phase shift allows the main source RMS current to change by almost $25 \%$ without major impact on phase current. In case when UC voltage is not sufficient for continuous six step switching or required power split in mode II cannot be met, then the mix switching operation has to be used. Typical waveforms for mixed operation including mode II and IV with switch angle $\alpha=\pi / 12$ are presented in Fig.22. The mode change will not introduce switching ripples other that ripples specific to the modulation mode. In the presented example 


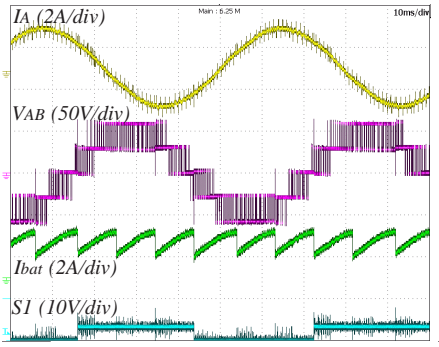

(a) Phase shift $\chi+\phi>0$

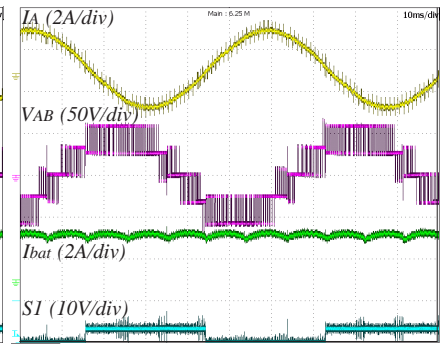

(b) Phase shift $\chi+\phi=0$
Fig. 21: Motor phase current $\left(I_{A}\right)$, phase to phase voltage $\left(V_{A B}\right)$, battery current $\left(I_{b a t}\right)$ and 3 phase bridge phase A gate signal $(S 1)$ in switching mode II for two values of phase shifts.

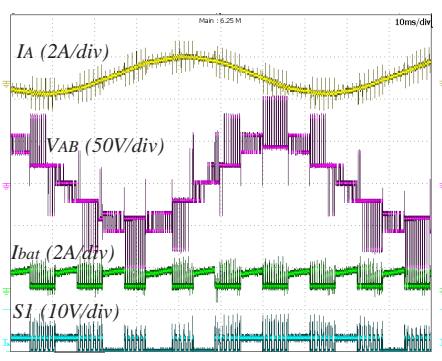

(a) Full waveform

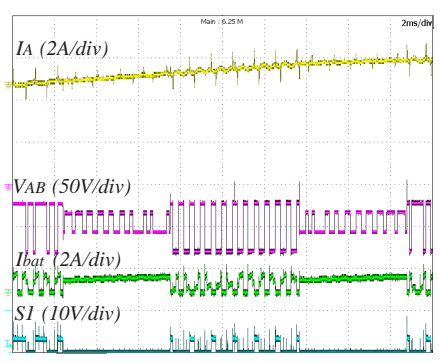

(b) Zoomed trace
Fig. 22: Motor phase current $\left(I_{A}\right)$, phase to phase voltage $\left(V_{A B}\right)$, battery current $\left(I_{b a t}\right)$ and 3 phase bridge phase A gate signal $(S 1)$ alternated switching between modulation in mode II and IV for $\alpha=\pi / 12$.

the amplitude of the main source is around three times bigger than amplitude of UC what is related with around three times higher current ripples when main source is used in SVM. In Fig.23, the harmonic analysis proves that mixed modulation scheme has harmonic content that is proportional to average level of two modulation schemes. Fig.24 shows another example where maximum output from inverter is generated and the ratio between sources voltage is close to four. This produces maximum number of levels (six voltage levels in phase to phase voltage) which helps to minimise ripples in motor current. Since between vectors in mode II empty spaces might start to appear as UC discharge and power sharing is limited, the modulation in mode VI is activated. Because the

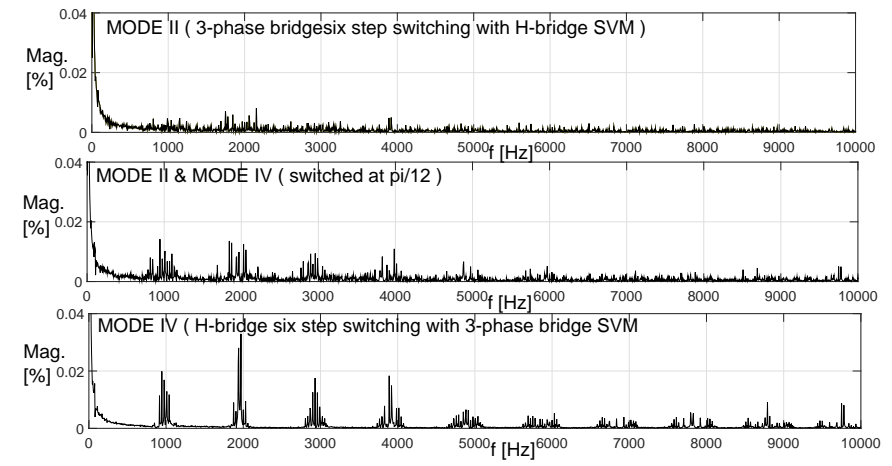

Fig. 23: Harmonic content ( in \% ) in phase current for modulation in mode II, mixed mode including switching II and IV for $\alpha=\pi / 12$ and mode IV (carrier frequency 977Hz).

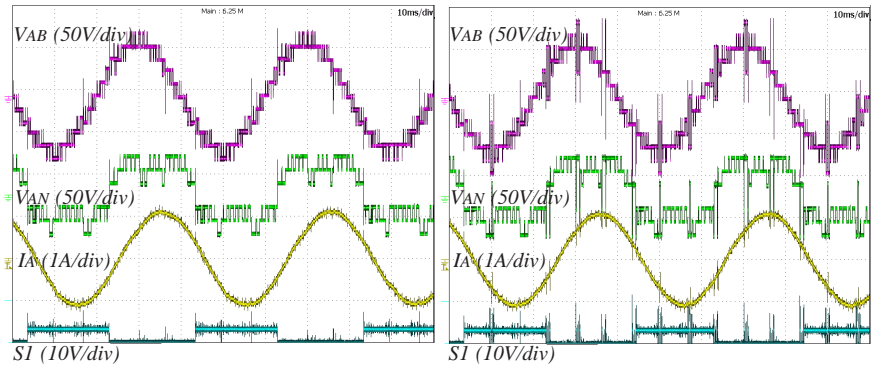

(a) Mode II only

(b) Mode II with added mode VI

Fig. 24: Motor phase current $\left(I_{A}\right)$, phase to phase voltage $\left(V_{A B}\right)$, phase voltage $\left(V_{A N}\right)$ and 3-phase bridge phase A gate signal ( $S 1)$ for modulation in mode II and mixed mode II with mode VI when capacitor voltage drops .

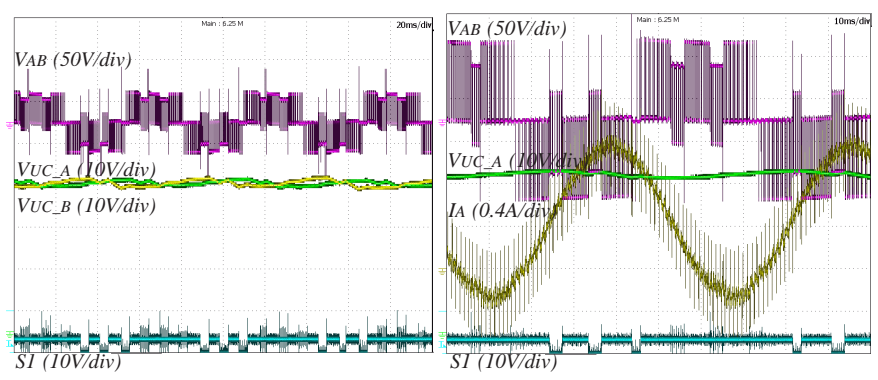

(a) Variation during three periods

(b) Zoomed view

Fig. 25: Motor phase phase to phase voltage $\left(V_{A B}\right)$, phase current $\left(I_{A}\right)$, capacitor voltages $\left(V_{U C_{A}}\right.$ and $\left.V_{U C_{B}}\right)$ and 3 phase bridge phase A gate signal ( $S 1$ ) for capacitors voltage level control for mixed mode II and III and low reference output voltage.

percentage of mode VI in modulation is small, the increase in motor current ripples is insignificant.

Mixed modulation strategy is found to be also efficient for capacitors voltage control. In experiment with $2 \mathrm{mF}$ capacitance as a source for H-bridge, it was proven that for whole range of output voltage it was possible to keep capacitors voltage with constant amplitude. Fig. 25 captures the waveforms showing variation of capacitors voltage where the average value remains stable (around $35 \mathrm{~V}$ where $V_{\text {bat }}$ is $62 \mathrm{~V}$ ) and only small variations related with its switching appears. The amplitude of modulated output voltage is $20 \mathrm{~V}$ so mode II altered with mode III is used. The variation in capacitors voltage does not disturb SVM so the quality of phase current is not affected. For higher amplitude of output voltage the phase shift regulation of capacitors voltage become more adequate. In Fig. 26 the output voltage from inverter in six step operation is presented. It is noted that capacitors voltage is kept at constant value and capacitors in phase A and B have same amplitude (Fig.26a). The second picture (Fig.26b) shows the case where capacitors are charged to $50 \mathrm{~V}$ and the new reference voltage of $25 \mathrm{~V}$ has been set. The energy transfer has been accomplished by phase shift in mode II with all capacitors reaching same set point.

Power management algorithm has also been validated during motor acceleration with aims to provide smooth battery 


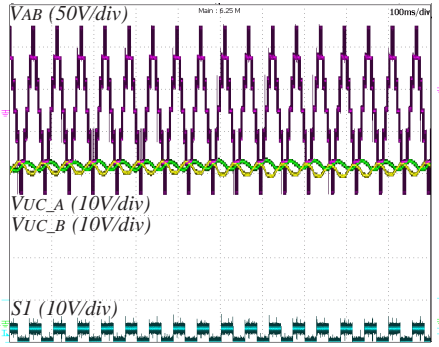

(a) Zoomed steady state

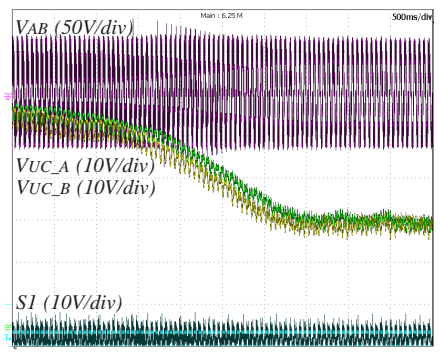

(b) Transient respond on $V_{U C_{r}}$ ef change

Fig. 26: Motor phase phase to phase voltage $\left(V_{A B}\right)$, capacitor voltages $\left(V_{U C_{A}}\right.$ and $\left.V_{U C_{B}}\right)$ and 3 phase bridge phase A gate signal $(S 1)$ for capacitors voltage level control in mode II modulation with phase shift and its respond to capacitors reference voltage change.

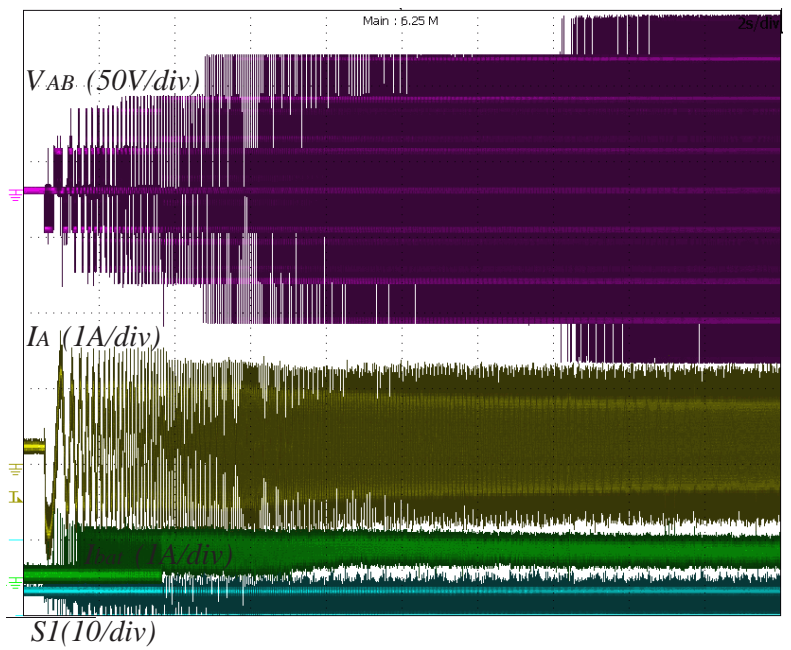

Fig. 27: Motor phase phase to phase voltage $\left(V_{A B}\right)$, phase current $\left(I_{A}\right)$, battery current $\left(I_{b a t}\right)$ and 3 phase bridge phase A gate signal $(S 1)$ during motor acceleration form 0rpm to 2000rpm with battery current control.

current rise and to avoid its average value to increase over set threshold. Fig. 27 shows the profile where the motor is accelerating from zero up to 2000rpm with fully charged UC $\left(V_{b a t}=2 V_{u c}\right)$. During acceleration first mode III is used to cope with initial inrush current and then gradually the three-phase bridge starts to operate (mode II with mode III). After the point where reference voltage is high enough the inverter changes the operation with three-phase bridge in sixstep switching (mode II). To limit current seen by the main source, the inverter initially operates with maximum phase shift " $\chi$ " angle, and as motor current decreases the phase shift is reduced, which can be observed as reduced ripples in the main source current $\left(I_{b a t}\right)$.

\section{CONCLUSION}

A novel modulation control method has been presented for the topology of a multi-level multisource inverter together with detailed analysis of its limitation. The method has been validated by experimental tests with control algorithm implemented on the C-Rio platform with FPGA. The same

proved to be feasible solution for hardware implementation what provides opportunities for practical designs. From the experimental results, it is evident that the proposed system can fully utilize UC and can increase output voltage in comparison to conventional three-phase bridges. The results also show that proposed multilevel configuration provides an effective method of power flow management between battery and $\mathrm{UC}$, and is able to provide stable output during transient operation and at the same time to enhance the steady state performance of the drivetrain. The first version of this paper has been presented in the IEEE Energy Conversion Congress and Exposition (ECCE 2016) [23].

\section{REFERENCES}

[1] P. R. Mati , A. Z. Raki, S. N. Vukosavi, Stator Voltage Vector Direct Torque Control of Induction Machine,Proc. Power Electronics and Motion Control Conference (EPE/PEMC), 2012 15th International, DS2a.13-1-8

[2] D. G. Stnescu, I. R. Bojoi , P. M. Nicolae, Dynamic Performance of a Speed Sensorless Induction Motor Drive with Flux Weakening Operation, Proc. Conference on Applied and Theoretical Electricity (ICATE), 2012 15th International, ,pp 1-5

[3] R. Schupbach, J. C. Balda, The Role of Ultracapacitors in an Energy Storage Unit for Vehicle Power Management, submitted for publication to IEEE Vehicular Technology Conference, Orlando, Florida, October 4th-9th 2003, pp. 3236 - 3240 Vol.5

[4] I.Aharon, A. Kuperman, Topological overview of power trains for batterypowered vehicles with range extenders, IEEE Transactions on Power Electronics, vol. 26, no. 3, pp. 868-876, 2011

[5] G. Guidi , T. M. Undeland ,Y. Hori, Effectiveness of Supercapacitors as Power-Assist in Pure EV Using a Sodium-Nickel Chloride Battery as Main Energy Storage, Proc. EVS24 International Battery, Hybrid and Fuel Cell Electric Vehicle Symposium ,2009, 1- 9

[6] R. Carter, A. Cruden, P. J. Hall, Optimizing for efficiency or battery life in a battery/supercapacitor electric vehicle, IEEE Transactions on Vehicular Technology, vol. 61, no. 4, pp. 1526-1533, 2012

[7] G. Guidi, T. G. Undeland, and Y. Hori, An Optimized Converter for Battery-Supercapacitor Interface, in proc. IEEE Power Electronics Specialists Conference, 2007, pp. 2976-2981

[8] P. J. Grbovi , P. Delarue , P. Le Moigne and P. Bartholomeus, The ultracapacitor based controlled electric drives with braking and ridethrough capability: Overview and analysis, IEEE Transactions on Industrial Electronics, vol. 58, no. 3, pp. 925-936, 2011

[9] Shuai Lu, K. A. Corzine , M. Ferdowsi, A New Battery/Ultracapacitor Energy Storage System Design and Its Motor Drive Integration for Hybrid Electric Vehicles, IEEE Transactions on Vehicular Technology, vol. 56, no. 4, pp. 1516-1523, 2007

[10] D. Krug , S. Bernet,; S. S, Fazel, K. Jalili, M. Malinowski, Comparison of 2.3-kV Medium-Voltage Multilevel Converters for Industrial MediumVoltage Drives, IEEE Transactions on Industrial Electronics, Vo. 54, no. 6, Dec. 2007 , pp. 2979-2992

[11] F. Khoucha, S. M. Lagoun, K. Marouani, A. Kheloui, M. E. H. Benbouzid, Hybrid cascaded H-bridge multilevel inverter motor drive DTC control for Electric Vehicles 18th International Conference on Electrical Machines. 2008 Pages: 1 - 6

[12] F. Khoucha, M. S. Lagoun, A. Kheloui, M. E. H. Benbouzid , A Comparison of Symmetrical and Asymmetrical Three-Phase H-Bridge Multilevel Inverter for DTC Induction Motor Drives IEEE Transactions on Energy Conversion, Vol. 26, no. 1, 2011, pp. 64 - 72

[13] Z. Du, B. Ozpineci , L. M. Tolbert and J. N. Chiasson, DC-AC cascaded $H$-bridge multilevel boost inverter with no inductors for electric/hybrid electric vehicle applications, IEEE Transactions on Industry Applications, vol. 45, no. 3, pp. 963-970, 2009

[14] S.Lu, K.A.Corzine, M.Ferdowsi,A unique ultra capacitor direct integration scheme in multilevel motor drives for large vehicle propulsion, IEEE Transactions on Vehicular Technology, vol. 56, no. 4, (2007) July, pp. 1506-15.

[15] S. D. G. Jayasinghe, D. M. Vilathgamuwa, U. K. Madawala, An analysis on the possibility of using capacitors of a three-level capacitor clamped inverter as power smoothing elements for wind power systems, in Proc. IEEE Energy Conversion Congress and Exposition, ECCE 2011, pp.29632970, 2011 
[16] S. Khomfoi, N. Praisuwanna, A hybrid cascaded multilevel inverter for interfacing with renewable energy resources The 2010 International Power Electronics Conference - ECCE ASIA , 2010, pp. 2912 - 2917

[17] A. L. Batschauer,; S. A. Mussa , M. L. Heldwein, Three-Phase Hybrid Multilevel Inverter Based on Half-Bridge Modules, IEEE Transactions on Industrial Electronics, Vol. 59, no. 2, 2012, pp. 668 - 678

[18] M. K. Menshawi, M. N. A. Kadir, S. Mekhilef Voltage Vector Approximation Control of MultistageMultilevel Inverter Using Simplified Logic Implementation, IEEE Transactions on Industrial Informatics, Vol, 9, no 4, Nov. 2013 pp. 2052-2062

[19] Z. Du, L.M. Tolbert, B.Ozpineci, J.N.Chiasson, Fundamental frequency switching strategies of a seven-level hybrid cascaded $\mathrm{H}$-bridge multilevel inverter, IEEE Transactions on Power Electronics, vol. 24, no. 1, pp.2533, 2009

[20] B.P. McGrath, D.G. Holmes, T. Lipo, Optimized Space Vector Switching Sequences For Multilevel Inverters, IEEE Transactions on Power Electronics, vol. 18, no.6, 2003, pp. 1293-1301

[21] L. Rosario, P. Luk, J. Economou, B. White, A modular power and energy management structure for dual-energy source electric vehicles, Proc. IEEE Vehicle Power and Propulsion Conference, pp. 1-6, 2006

[22] F. Bishuang, T. Guanzheng, Fan Shaosheng, Comparison of Three Different 2-D Space Vector PWM Algorithms and Their FPGA Implementations, Proc. Journal of Power Technologies 94 (3) ,2014, 176189

[23] M. Bendyk, P. C.-K. Luk, Control strategy for a modified cascade multilevel inverter with dual DC source for enhanced drivetrain operation, in Proc. 2016 IEEE Energy Conv. Cong. and Expo. (ECCE), Milwaukee, WI, USA, pp. 1 - 8, DOI: 10.1109/ECCE.2016.7854971 